Rabaska

Revue d'ethnologie de l'Amérique française

\title{
Le Centre de conservation du Québec
}

\section{Delphine Laureau}

Volume 15, 2017

URI : https://id.erudit.org/iderudit/1041163ar

DOI : https://doi.org/10.7202/1041163ar

Aller au sommaire du numéro

Éditeur(s)

Société québécoise d'ethnologie

ISSN

1703-7433 (imprimé)

1916-7350 (numérique)

Découvrir la revue

Citer ce document

Laureau, D. (2017). Le Centre de conservation du Québec. Rabaska, 15, 315-317. https://doi.org/10.7202/1041163ar

Ce document est protégé par la loi sur le droit d'auteur. L'utilisation des services d'Érudit (y compris la reproduction) est assujettie à sa politique d'utilisation que vous pouvez consulter en ligne.

https://apropos.erudit.org/fr/usagers/politique-dutilisation/
Cet article est diffusé et préservé par Érudit.

Érudit est un consortium interuniversitaire sans but lucratif composé de l’Université de Montréal, l’Université Laval et l’Université du Québec à Montréal. Il a pour mission la promotion et la valorisation de la recherche. https://www.erudit.org/fr/ 


\title{
Complémentarité et partenariat
}

Désireux de travailler en complémentarité avec ses pairs, le Musée procède à la captation ou prête des récits et témoignages. Le Centre Juno de Courseulles-sur-Mer, le Musée de Gaspé, le Musée québécois de l'agriculture et de l'alimentation et le Musée maritime du Québec présentent dans quelques-unes de leurs expositions des témoignages recueillis par le Musée. Un travail de partenariat est également fait avec de nombreux organismes répartis dans plusieurs régions du Québec. Ces organismes sont préalablement initiés aux techniques d'enquête de terrain et au traitement des témoignages selon les méthodes du Musée. Tous les témoignages recueillis sont joints à la collection qui est accessible pour écoute à la salle de consultation. En 2016, les organismes partenaires suivants ont collecté et déposé des témoignages au Musée : la MrC des Basques, la Maison Léon-Provancher à Cap-Rouge, le BeauLieu culturel du Témiscouata, la Société historique de Rivière-des-Prairies, le Comité de développement de Saint-Germain-de-Kamouraska, et la SÉPAQ (Parcs Québec) : Parcs nationaux du Bic, de Frontenac, de la Gaspésie, du Fjord-du-Saguenay, et Parc marin du Saguenay-Saint-Laurent. En juin 2016, la Société québécoise d'ethnologie et le Musée de la mémoire vivante ont signé une entente de partenariat.

\section{Perspectives d'avenir}

L'exposition permanente Souvenirs de table sera remplacée en 2018 par Excusez-la! dont la thématique sera la chanson traditionnelle.

Le financement demeure l'une des activités essentielles du Musée qui ne reçoit aucune subvention récurrente, outre celle de la Municipalité de Saint-Jean-Port-Joli. C'est pourquoi il a créé un fonds de dotation perpétuel dans le cadre du programme « Mécénat Placement culture » afin d'assurer la sauvegarde de sa collection.

Judith DouviLle

\section{Le Centre de conservation du Québec}

\author{
1825 , rue Semple \\ Québec (Québec) \\ G1N 4B7
}

Téléphone : (418) 643-7001

Courriel : ccq@mcc.gouv.qc.ca

Toile : www.ccq.gouv.qc.ca

Au cours de 2016-2017, l'équipe de restaurateurs professionnels en réponse à la mission du Centre de conservation du Québec, direction du ministère de la Culture et des Communications :

1. a fourni plus de 30000 heures de services professionnels d'expertise-diagnostic, de rôle-conseil et de restauration de biens patrimoniaux

Rapports de constat d'état patrimonial. Plusieurs rapports d'état patrimonial ont été produits pour le bénéfice des propriétaires et du ministère de la Culture et des communications tel qu'un rapport exhaustif sur l'historique et l'état patrimonial d'une goélette, bien patrimonial classé. 
Collaboration avec les institutions muséales. Le Centre travaille à adapter son plan d'intervention d'urgence en cas de sinistre pour répondre aux besoins des modestes et petites institutions soutenues au fonctionnement par le ministère de la Culture et des communications, y compris les centres d'interprétation. Ce projet comprend plusieurs phases et s'étale sur plus de trois ans.

Restaurations majeures. La restauration du décor peint de la voûte centrale de l'église de Saint-Romuald, bien patrimonial classé, a demandé 3300 heures de travail et a mobilisé 13 restaurateurs spécialisés et 1 technicien. Ces heures ont été consacrées au dépoussiérage, au nettoyage, à la consolidation du support et des couches picturales, au comblement et à la consolidation des fissures et des délaminations, à la réfection de l'enduit, à la consolidation de clefs de voûte et finalement à de la retouche de couleurs.

Depuis 30 ans, plus de 40 tableaux religieux de grand format faisant partie d'un ensemble de plus de 180 tableaux appelés les « tableaux Desjardins » transportés de la France au Québec en 1817 et 1820 ont été restaurés par le Centre de conservation. De nombreuses heures de restauration ont été consacrées à ces tableaux provenant du fonds des tableaux Desjardins et exposés à l'été 2017 au Musée national des beaux-arts du Québec et dont plusieurs retraverseront l'Atlantique pour être exposés au Musée des beaux-arts de Rennes, en France.

2. a encouragé le développement de la connaissance, des compétences et des aménagements nécessaires à la meilleure conservation du patrimoine dans une perspective de développement durable

Des formations en conservation préventive. Une formation théorique et pratique sur l'entreposage à très basse température des documents photographiques sur support souple, soit la méthode CMI adaptée aux congélateurs domestiques, a été dispensée aux membres du Regroupement des services d'archives privées agréées du Québec (RSAPAQ). Des artistes en art textile ont été sensibilisés aux problèmes de conservation des œuvres textiles ainsi qu'à l'importance de rédiger un constat d'état de leurs œuvres lors d'un transport ou d'un prêt. Les façons de faire ainsi que le vocabulaire pour identifier et localiser les altérations des œuvres textiles leur a été présenté.

\section{Publication d'un guide technique consacré à la couverture en bardeaux de bois}

Le Centre de conservation du Québec et les Publications du Québec ont publié conjointement Toit. Bois. Bardeau. Guide technique, le premier guide québécois entièrement consacré à la couverture en bardeaux de bois. Produit par deux restaurateurs de l'atelier Bois du CCQ, cet ouvrage de référence, adapté aux réalités et au climat nord-américains, a pour objectif d'aider à maximiser la durée de vie de ce type de couverture. Il a été lancé à l'automne 2016.

Un prix prestigieux. M. André Bergeron, restaurateur depuis 1980 à l'atelier des objets archéologiques et ethnologiques du Centre de conservation du Québec, a reçu le prestigieux prix Charles-Mervyn-Ruggles pour sa contribution exemplaire au domaine de la conservation. Ce prix, décerné par l'Association canadienne pour la conservation et la restauration des biens culturels (ACCR), lui a été remis à l'occa- 
sion du $42^{\circ}$ congrès annuel de l'ACcR tenu conjointement avec celui de l'American Institute for Conservation of Historic \& Artistic Works, en mai 2016. M. Bergeron est le premier francophone à recevoir ce prix.

Delphine Laureau

\title{
Chaire de recherche du Canada en patrimoine ethnologique
}

6115, Pavillon Jean-Charles-Bonenfant

Université Laval

2345, allée des Bibliothèques

Téléphone : (418) 656-7200

Québec (Québec)

G1V 0A6

\author{
Courriel : Laurier.Turgeon@hst.ulaval.ca
}

Toile : www. chaire-patrimoine.ulaval.ca

En 2016-2017, la Chaire de recherche du Canada en patrimoine ethnologique de l'Université Laval, dirigée par Laurier Turgeon, a été occupée principalement par le projet du Corridor patrimonial, culturel et touristique francophone du Canada. Ce projet national a pour but de mettre en valeur les communautés francophones d'un bout à l'autre du pays. Il vise plus particulièrement à faire découvrir les attraits patrimoniaux, culturels et touristiques de la francophonie canadienne à l'ensemble des Canadiens et aux visiteurs étrangers, francophones et francophiles. Piloté par le Réseau de développement économique du Canada (RDÉE-Canada), le projet est principalement financé par le ministère du Patrimoine canadien, dans le cadre du $150^{\mathrm{e}}$ anniversaire de la Confédération.

La Chaire est mandatée pour réaliser les contenus à caractère patrimonial et culturel. L'équipe de la Chaire témoignera de la vitalité actuelle des communautés francophones par le biais de capsules vidéo réalisées avec des acteurs du milieu, lors d'événements ou dans des endroits particulièrement signifiants. Cent cinquante sujets, lieux et événements patrimoniaux et culturels ont été sélectionnés, dont une cinquantaine de l'est du Canada, y compris l'Acadie, une cinquantaine du Québec et une cinquantaine de l'Ontario et de l'Ouest du Canada. Une série de textes informatifs présentera leur réalité actuelle et leur histoire. Des images d'archives, des photographies contemporaines, des archives orales, des cartes interactives et des reconstitutions 3D compléteront la couverture du patrimoine culturel francophone. Deux cents sujets supplémentaires, à caractère touristique, s'ajoutent aux circuits qui seront proposés aux visiteurs pour leur faire découvrir l'apport des francophones à la société canadienne. Ces contenus multimédias seront diffusés sur un site web et des applications mobiles, des technologies numériques qui révèlent de façon attrayante et novatrice les dimensions humaines et la vivacité culturelle des communautés francophones.

Lancé en septembre 2017, le projet Corridor contribuera au développement économique et culturel, ainsi qu'au rayonnement de la francophonie canadienne, en renforçant le sentiment d'appartenance et l'unité des francophones canadiens.

LAURIER TURGEON 